\title{
Coronin 3 negatively regulates G6PC3 in HepG2 cells, as identified by label-free mass-spectrometry
}

\author{
YUNZHEN GAO ${ }^{1,2}$, LING LI $^{3}$, XIAOHUA XING ${ }^{1,2}$, MINJIE LIN $^{1,2}$, \\ YONGYI ZENG ${ }^{1-3}$, XIAOLONG LIU ${ }^{1,2}$ and JINGFENG LIU ${ }^{1-3}$

\begin{abstract}
${ }^{1}$ The United Innovation of Mengchao Hepatobiliary Technology Key Laboratory of Fujian, Mengchao Hepatobiliary Hospital of Fujian Medical University; ${ }^{2}$ The Liver Center of Fujian, Fujian Medical University; ${ }^{3}$ Liver Disease Center, The First Affiliated Hospital of Fujian Medical University, Fuzhou, Fujian 350005, P.R. China
\end{abstract}

Received July 20, 2016; Accepted April 28, 2017

DOI: $10.3892 / \mathrm{mmr} .2017 .7002$

\begin{abstract}
Human coronin 3 is involved in many types of cancers, but the underlying molecular mechanisms require further elucidation. The present study demonstrated that coronin 3 is significantly upregulated in clinical primary hepatocellular carcinoma (HCC) samples by reverse transcription-quantitative polymerase chain reaction (RT-qPCR) and immunohistochemical staining. Subsequently, proteins that were regulated by coronin 3 in both coronin 3 overexpressing or knocked down HepG2 cells were analyzed by label free mass spectrometry; overall, 249 proteins were identified to be closely regulated by coronin 3 , and those coronin 3 regulated proteins were enriched in cellular, physiological and metabolism processes. By further in-depth pathway analysis, it was demonstrated that those proteins were involved into 94 different pathways. Finally, the expression levels of glucose-6-phosphatase catalytic subunit 3 (G6PC3) were confirmed to be negatively regulated by coronin 3, as determined by RT-qPCR and western blotting. In conclusion, these results indicated that coronin 3 is significantly dysregulated in HCC tumor tissues, and may exert its function via regulating G6PC3 expression. These results provide valuable information for further study of coronin 3-mediated signaling pathways, and implicate coronin 3 as a potential therapeutic target for HCC.
\end{abstract}

\section{Introduction}

Coronin 3, a short protein of 474 aa, is the most widely expressed coronin protein in mammals and localizes to

Correspondence to: Professor Xiaolong Liu or Professor Jingfeng Liu, The United Innovation of Mengchao Hepatobiliary Technology Key Laboratory of Fujian, Mengchao Hepatobiliary Hospital of Fujian Medical University, 312 Xihong Road, Fuzhou, Fujian 350005, P.R. China

E-mail: xiaoloong.liu@gmail.com

E-mail: drjingfeng@126.com

Key words: coronin 3, proteomics, glucose-6-phosphatase catalytic subunit 3 , hepatocellular carcinoma, mass spectrometry lamellipodia (1-4). It has been reported that coronin 3 may interact with actin-related protein $2 / 3$ (Arp2/3) and negatively regulate actin polymerization (5). In addition, coronin 3 may negatively regulate cell motility by regulating cell-matrix adhesion via focal adhesion kinase (6).

Human coronin 3 is involved in many types of cancers, including diffuse gliomas (7), lung cancer (8), gastric cancer (9) and hepatocellular carcinoma (HCC) (10). It has been reported that the expression level of coronin 3 in the HCCLM97H HCC cell line (high metastasis capacity) was significantly increased compared with in the MHCC97L cell line (low metastasis capacity) (11); and the increased expression of coronin 3 was strongly associated with tumor spontaneous pulmonary metastasis in a nude mouse model of HCC. Furthermore, coronin 3 enhances cell motility and proliferation; knockdown of coronin 3 in BEL-7402 cells reduces the stress fiber network, decreases lamellipodial extension and attenuates the malignant potential of BEl-7402 cells in mice (10). In clinical HCC tissues, coronin 3 was significant differently expressed among HCC specimens of different clinical stages; compared with early stage (Barcelona Clinic Liver Cancer I and II) tumor tissues, the later stage (Barcelona Clinic Liver Cancer III and IV) tumor tissues had significantly stronger staining of coronin 3 (28.6 and $46.7 \%$, respectively) (11).

It has been reported that coronin 3 could enhance activation of Ras-related C3 botulinum toxin substrate 1 precursor (Rac-1), a Rho family small GTPase $(10,12)$, but little is known about the molecular mechanisms or proteins that are regulated by coronin 3 . Therefore, the present study aimed to analyze the expression levels of coronin 3 in HCC clinical tissue samples by reverse transcription-quantitative polymerase chain reaction and immunohistochemical staining, and further analyze the proteins regulated by coronin 3 using mass spectrometry in HCC cell lines where coronin 3 was stably overexpressed or knocked down.

\section{Materials and methods}

Ethics statement. The use of human biopsies in the present study was ethically approved by the Institution Review Board of Mengchao Hepatobiliary Hospital of Fujian Medical 
University (Fuzhou, China). Written consent was received from all participants at the time of surgery.

Clinical samples. A total of 20 fresh-frozen primary HCC tissues and their corresponding adjacent non-tumorous samples (basic information is presented in Table $\mathrm{I}$ ) and 98 pairs of paraffin-embedded primary HCC tissues were collected during surgical resection at Mengchao Hepatobiliary Hospital of Fujian Medical University, and stored in the tissue bank for further usage.

RNA extraction. Trizol reagent (Invitrogen; Thermo Fisher Scientific, Inc., Waltham, MA, USA) was used to extract total RNA from clinical samples and cell lines according to the manufacture's protocol. The spectrophotometer (Nano Drop ND-2000, Thermo Fisher Scientific Inc.) was used to measure the concentration and purity of RNAs through the optical density of 260/280 readings. RNA integrity was determined by $1 \%$ formaldehyde denaturing gel electrophoresis.

$R T$-qPCR analysis. RNA $(1 \mu \mathrm{g})$ was reverse transcribed using a GoScript ${ }^{\mathrm{TM}}$ Reverse Transcription System kit (Promega Corporation, Madison, WI, USA) in accordance with the manufacturer's protocol. The expression levels of coronin 3 and associated genes were analyzed using RT-qPCR with a Go $\mathrm{Taq}^{\circledR}$ qPCR Master Mix kit (Promega Corporation) in accordance with manufacturer's protocol, using the primers listed in Table II. The reaction system $(20 \mu \mathrm{l})$ was as follows: qPCR Master mix (2X), $10 \mu \mathrm{l}$; forward primer $(10 \mathrm{nM}), 0.2 \mu \mathrm{l}$; reverse primer $(10 \mathrm{nM}), 0.2 \mu \mathrm{l}$; cDNA, $50 \mathrm{ng}$; finally supplemented with water to $20 \mu$ l. qPCR was performed on StepOne Plus PCR system (Applied Biosystems; Thermo Fisher Scientific, Inc.) with the following parameters: Pre-denaturing at $95^{\circ} \mathrm{C}$ for $2 \mathrm{~min}$; cycling at $95^{\circ} \mathrm{C}$ for $15 \mathrm{sec} ; 60^{\circ} \mathrm{C}$ for $20 \mathrm{sec} ; 72^{\circ} \mathrm{C}$ for $20 \mathrm{sec}$ (collect the signature at this step), for a total of 40 cycles; followed by the melt curve stage: $95^{\circ} \mathrm{C}$ for $15 \mathrm{sec}$, $60^{\circ} \mathrm{C}$ for $1 \mathrm{~min}$ and $90^{\circ} \mathrm{C}$ for $30 \mathrm{sec}$, with a reading signature of per $0.3^{\circ} \mathrm{C}$ from 60 to $90^{\circ} \mathrm{C}$ ). $\beta$-actin served as an internal control and the $2^{-\Delta \Delta C q}$ method (13) was used to calculate the expression levels of genes.

Cell culture, plasmid construction, transient transfection and establishment of stable overexpression and knockdown of coronin 3 in HepG2 cell lines. The HepG2 human HCC cell line was obtained from The Cell Bank of Chinese Academy of Sciences (Shanghai, China). The cells were cultured in minimum essential medium (MEM) supplemented with $10 \%$ fetal bovine serum (FBS) at $37^{\circ} \mathrm{C}$ in $5 \% \mathrm{CO}_{2}$. For the establishment of coronin 3 stably over-expressing cells, the coding sequence of coronin 3 was cloned into a pLVX-AcGFPI-N1 plasmid. Then the plasmid was co-transfected into 293T cells with three lentiviral packaging plasmids, pLP1, pLP2 and pLP VSV-G. For the establishment of knockdown cells, small hairpin RNAs (shRNAs) were used to specifically reduce coronin 3 expression in HepG2 cells as follows: The shRNA oligo 5'-CGTCCACTACCTCAACACATT-3' was cloned into pGreenPuro (System Biosciences, Inc., Palo Alto, CA, USA); the shRNA plasmid was subsequently co-transfected into 293T cells with lentiviral packaging plasmids, and the resulting lentiviruses were collected and used to infect the target HepG2 cells. The HepG2 cells were spread in a T75 flask $24 \mathrm{~h}$ after infection for a subsequent 1-week incubation in MEM supplemented with $2 \mu \mathrm{g} / \mathrm{ml}$ puromycin. Cells infected with the empty vectors were used as control transfectants. Stable overexpression and stable knockdown of coronin 3 were confirmed by RT-qPCR and western blot analysis.

Immunohistochemical staining assay. Primary HCC tissues and their corresponding adjacent non-tumorous samples were fixed with $4 \%$ paraformaldehyde, embedded in paraffin and sectioned. The sections were dried at $60^{\circ} \mathrm{C}$ for $2 \mathrm{~h}$ and then de-waxed and rehydrated. Antigens were retrieved by microwave in EDTA $(1 \mathrm{mM})$. Subsequently, the sections were stained with a mouse anti-coronin 3 antibody (catalog no. sc-376919, 1:100, Santa Cruz Biotechnology, Inc., Dallas, TX, USA) at $4^{\circ} \mathrm{C}$ overnight, then incubated with a secondary antibody (catalog no. HS201-01, Beijing Transgen Biotech Co., Ltd., Beijing, China) for $2 \mathrm{~h}$ at room temperature. The sections were finally visualized using a DAB substrate chromogen system (Dako; Agilent Technologies, Inc., Santa Clara, CA, USA) according to the manufacturer's protocol.

Western blot analysis. Cells were washed in pre-cold PBS at $4^{\circ} \mathrm{C}$ and lysed in radioiummunoprecipitation buffer $(20 \mathrm{mM}$ Tris, pH 7.4, $150 \mathrm{mM} \mathrm{NaCl}, 1 \%$ Triton X-100, $1 \%$ Na deoxycholate, $2 \mathrm{mM}$ EGTA, $2 \mathrm{mM}$ EDTA, $0.1 \%$ SDS) containing protease inhibitor cocktail (Thermo Fisher Scientific, Inc.) and phosphatase inhibitor cocktails (Sigma-Aldrich; Merck KGaA, Darmstadt, Germany). Lysates were centrifuged at $17,000 \mathrm{x}$ g for $30 \mathrm{~min}$ at $4^{\circ} \mathrm{C}$. Protein concentration was determined using a Bicinchoninic Acid protein quantification assay. Proteins $(50 \mu \mathrm{g})$ were separated by $10 \%$ SDS-PAGE and blocked with $5 \%$ bovine serum albumin (catalog no. A7906-1KG, Sigma-Aldrich) in TBST (20 mM Tris-HCl, $500 \mathrm{mM} \mathrm{NaCl}(\mathrm{pH} 7.5)$ and $0.1 \%$ Tween 20 ) at room temperature for $2 \mathrm{~h}$, and then incubated with mouse anti-coronin 3 (catalog no. sc-376919, Santa Cruz Biotechnology, Inc., 1:500) and anti- $\beta$-actin (catalog no. 04693132001, 1:1,000, Transgene, Beijing, China) primary antibodies at $4^{\circ} \mathrm{C}$ overnight. Subsequently, membranes were incubated with corresponding secondary antibodies (catalog no. HS201-01, Beijing Transgen Biotech Co., Ltd.) at room temperature for 2 h. Finally, the results were visualized by enhanced chemiluminescence.

Label-free mass spectrometry (MS). The MS experiment was performed as previously described (14) with some modifications. Briefly, a total of $500 \mathrm{ng}$ proteins from the whole cell lysate of cells stably overexpressing and stably silencing coronin 3 were digested with $10 \mathrm{U} / 100 \mathrm{ng}$ trypsin. Following this, the peptide mixture was dried and re-dissolved in solution A (5\% acetonitrile and $0.1 \%$ formic acid in water, $\mathrm{pH} 10.0$ ), and then fractionated by high $\mathrm{pH}$ separation using an Agilent 1260 Infinity system (Agilent Technologies, Inc., Santa Clara, CA, USA) equipped with a reverse phase column (Durashell C18, $5 \mu \mathrm{m}, 4.6 \times 250 \mathrm{~mm}$, Tianjin Bonna-Agela Technologies, Co., Ltd., Tianjin, China). High pH separation was performed using a linear gradient starting from $20 \%$ B to $80 \%$ B in 90 min [solution B: $0.1 \%$ formic acid in $90 \%$ acetonitrile (can), $\mathrm{pH} 10.0]$ with a column flow rate at $700 \mu \mathrm{l} / \mathrm{min}$ and the column temperature at $45^{\circ} \mathrm{C}$. Finally, 40 fractions were collected. To 
Table I. Basic information of 20 hepatocellular carcinoma patients.

\begin{tabular}{|c|c|c|c|c|c|c|c|c|}
\hline Number & Age & Sex & $\begin{array}{c}\text { Tumor } \\
\text { diameter }(\mathrm{cm})\end{array}$ & $\begin{array}{l}\text { Tumor } \\
\text { number }\end{array}$ & $\begin{array}{c}\text { HBV-DNA } \\
\text { (copy number) }\end{array}$ & $\begin{array}{l}\text { Cirrhosis } \\
\text { grade }\end{array}$ & $\begin{array}{l}\text { Tumor } \\
\text { capsule }\end{array}$ & $\begin{array}{l}\text { Blood tumor } \\
\text { thrombosis }\end{array}$ \\
\hline 1 & 33 & Male & 4 & 1 & 1,110 & Low & Non & Yes \\
\hline 2 & 49 & Male & 11 & 1 & 323,000 & Low & Integrate & Yse \\
\hline 3 & 34 & Male & 7 & 1 & 151,000 & Sever & Non & Yes \\
\hline 4 & 37 & Male & 4 & 1 & 1280,000 & Low & Integrate & Yes \\
\hline 5 & 66 & Male & 11 & 1 & $<1,000$ & Non & Integrate & Yes \\
\hline 6 & 33 & Male & 14 & 1 & 3,290 & Low & Non & Yse \\
\hline 7 & 47 & Male & 16 & 1 & 40,000 & Low & Non & Yes \\
\hline 8 & 37 & Male & 10 & 1 & 2,800 & Non & Ruptured & Yes \\
\hline 9 & 46 & Male & 15 & 1 & 8,320 & Non & Non & Yes \\
\hline 10 & 61 & Male & 10.5 & 1 & 18,100 & Low & Integrate & No \\
\hline 11 & 61 & Male & 15 & 1 & 5,900 & Non & Integrate & Yes \\
\hline 12 & 46 & Male & 12 & 1 & 311,000 & Middle & Integrate & Yse \\
\hline 13 & 65 & Male & 11 & 1 & $<1,000$ & Non & Integrate & No \\
\hline 14 & 62 & Male & 6 & 4 & 582,000 & Middle & Integrate & Yes \\
\hline 15 & 44 & Female & 12 & 1 & 6,490 & Middle & Integrate & Yes \\
\hline 16 & 54 & Male & 5 & 1 & 7,990 & Meddle & Integrate & Yes \\
\hline 17 & 49 & Female & 8.5 & 1 & 1,070 & Non & Integrate & No \\
\hline 18 & 60 & Female & 3.5 & 1 & 3,980 & Non & Non & No \\
\hline 19 & 45 & Male & 11 & 1 & 8,260 & Middle & Integrate & No \\
\hline 20 & 54 & Male & 15 & 1 & $<1,000$ & Non & Non & No \\
\hline
\end{tabular}

HBV, hepatitis B virus.

Table II. Primer sequences used for reverse transcription-quantitative polymerase chain reaction.

\begin{tabular}{lll}
\hline Gene & \multicolumn{1}{c}{ Sequence } & Tm $\left({ }^{\circ} \mathrm{C}\right)$ \\
\hline$\beta$-actin & F: ATAGCACAGCCTGGATAGCAACGTAC & 60 \\
& R: CACCTTCTACAATGAGCTGCGTGTG \\
Coronin 3 & F: CTGCACAGCTTCCAAAGACAAGA & 60 \\
G6PC3 & R: GGCTGAACCCAGTGGTGAAGA \\
& F: TCTTCAAGTGGTTTCTTTTTGGAG \\
& R: GCTAGGCATCACCCTTACCC
\end{tabular}

Tm, thermocycling conditions; F, forward; R, reverse; G6PC3, glucose-6-phosphatase catalytic subunit 3

reduce the fraction numbers, two fractions with the same time interval were pooled together, such as 1 and 21, 2 and 22, and so on (14), and 20 fractions at the end were dried in a vacuum concentrator and stored at $-80^{\circ} \mathrm{C}$ for further usage.

The fractions were re-suspended with $80 \mu \mathrm{l}$ solution $\mathrm{C}$ $(0.1 \%$ formic acid in water), and separated by a Nano-LC1000 system (Waters Corporation, Milford, MA, USA) connected to a quadrupole-Orbitrap mass spectrometer (Q-Exactive Plus; Thermo Fisher Scientific, Inc.) equipped with an online nano-electrospray ion source nano-LC and analyzed by online electrospray tandem mass spectrometry. The experiment parameters were set as follows: $2 \mu 1$ peptide sample was loaded onto the trap column (Thermo Scientific Acclaim PepMap C18, $100 \mu \mathrm{mx} 2 \mathrm{~cm}$ ) with a flow rate at $10 \mu \mathrm{l} / \mathrm{min}$, and subsequently separated on an analytical column (Acclaim PepMap C18, $75 \mu \mathrm{mx} 15 \mathrm{~cm}$ ) with a linear gradient, from $3 \% \mathrm{D}$ to $35 \% \mathrm{D}$ in $60 \mathrm{~min}$ (solution D: $0.1 \%$ formic acid in $\mathrm{ACN}$ ) with flow rate at $300 \mathrm{nl} / \mathrm{min}$ and the column temperature at $40^{\circ} \mathrm{C}$ and an electrospray voltage of $2.8 \mathrm{kV}$. Survey full-scan MS spectra (m/z 300-1500) was acquired with a mass resolution of $70 \mathrm{~K}$, followed by 10 sequential high energies collisional dissociation MS/MS scans with a resolution of $17.5 \mathrm{~K}$. In all cases, one microscan was recorded using a dynamic exclusion of $30 \mathrm{sec}$.

Mass spectrometry data analysis. Label-free MS experiments were repeated 3 times (with 3 biological repeats), and the raw MS data was analyzed by MaxQuant V4.2 (http://www. maxquant.org) using the decoy UniProt-human database 
Table III. GO analysis results of 249 dysregulated proteins.

\begin{tabular}{lcc}
\hline GO term & Count & Percent (\%) \\
\hline GO:0009987 cellular process & 322 & 14.68978 \\
GO:0007582 physiological process & 297 & 13.54927 \\
GO:0008152 metabolism & 158 & 7.208029 \\
GO:0065007 biological regulation & 140 & 6.386861 \\
GO:0044464 cell part & 124 & 5.656934 \\
GO:0005623 cell & 124 & 5.656934 \\
GO:0050789 regulation of biological process & 121 & 5.520073 \\
GO:0003824 catalytic activity & 110 & 5.018248 \\
GO other items & 97 & 4.425182 \\
GO:0005488 binding & 84 & 3.832117 \\
GO:0043226 organelle & 83 & 3.786496 \\
GO:0032502 developmental process & 68 & 3.10219 \\
GO:0044422 organelle part & 64 & 2.919708 \\
GO:0032501 multicellular organismal process & 63 & 2.874088 \\
GO:0050896 response to stimulus & 58 & 2.645985 \\
GO:0051179 localization & 57 & 2.600365 \\
GO:0051234 establishment of localization & 53 & 2.417883 \\
GO:0032991 macromolecular complex & 40 & 1.824818 \\
GO:0048518 positive regulation of biological process & 38 & 1.733577 \\
GO:0048519 negative regulation of biological process & 28 & 1.277372 \\
GO:0005215 transporter activity & 24 & 1.094891 \\
GO:0002376 immune system process & 21 & 0.958029 \\
GO:0031974 membrane-enclosed lumen & 18 & 0.821168 \\
\hline
\end{tabular}

GO, Gene Ontology.

(Version April 2014, 20264 entries) supplemented with 262 frequently observed contaminants with forward and reverse sequences. Precursor mass and fragment mass were identified with an initial mass tolerance of 6 and $20 \mathrm{ppm}$ in the main Andromeda search, respectively. The search included variable modifications of $\mathrm{N}$-terminal acetylation, methionine oxidation and fixed modification of carbamidomethyl cysteine with 7aa as minimal peptide length and a maximum of two mis-cleavages and a false discovery rate of 0.01 . The identified peptides shared by two proteins or more were combined and reported as one protein group, and the peptides that matched the reverse database were filtered out.

The fold change of proteins was calculated through comparing the relative protein expression of coronin 3 over-expressing/knockdown cells with their corresponding control cells, and the mean average fold change was calculated from 3 replicates. The differentially expressed proteins were selected using the following criteria for average fold-change of protein expression levels compared with control cells: $>2$, upregulation; <0.5, downregulation.

Gene ontology and pathway analysis. The Molecular Annotation system (CB-MAS) V3.0 (http://bioinfo.capitalbio. $\mathrm{com} / \mathrm{mas} 3 /$ ) was used to perform protein ontology and pathway analysis. An 'input list' containing 249 proteins was introduced into MAS version 3.0 and the analysis was performed with default parameters (selecting all pathways in
Kyoto Encyclopedia of Genes and Genomes (KEGG) pathway database and perform KEGG analysis.

Ingenuity ${ }^{\circledR}$ pathway analysis (IPA) network analysis. To identify the potential associations among the differentially expressed proteins, identified proteins were subjected to IPA (Qiagen GmbH, Hilden, Germany; http://www.ingenuity.com). Accession numbers of differentially expressed proteins (with NCBI identities) and P-values obtained from Student's t-test were entered into Microsoft Excel and then imported into IPA to identify the relationships among proteins. The Ingenuity Knowledge Base was used to perform the construction of canonical pathways and interaction networks. Based on the hypergeometric distribution, the network score was calculated and tested using the right-tailed Fisher's exact test. The higher the score, the more relevant the eligible submitted proteins were in relation to the network.

Rac-1 activity analysis. Rac-1 activity was tested using 'Active Rac1 Pull-Down and Detection kit' (catalog no. 16118, Pierce; Thermo Fisher Scientific, Inc.). Briefly, the HepG2 cells were cultured in $75 \mathrm{~cm}^{2}$ flask to $80-90 \%$ confluency, and subsequently the culture medium was removed and the cells were rinsed once with ice-cold TBS, and $1 \mathrm{ml}$ lysis/binding/wash buffer $(25 \mathrm{mM}$ Tris- $\mathrm{HCl}$ at $\mathrm{pH} 7.2,150 \mathrm{mM} \mathrm{NaCl}, 5 \mathrm{mM}$ $\mathrm{MgCl}_{2}, 1 \% \mathrm{NP}-40$ and 5\% glycerol) was further added. Cells were scraped and transferred into a $1.5 \mathrm{ml}$ tube and incubated 
A

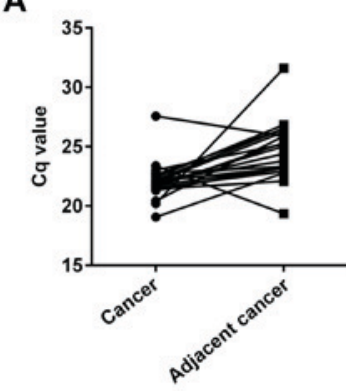

B

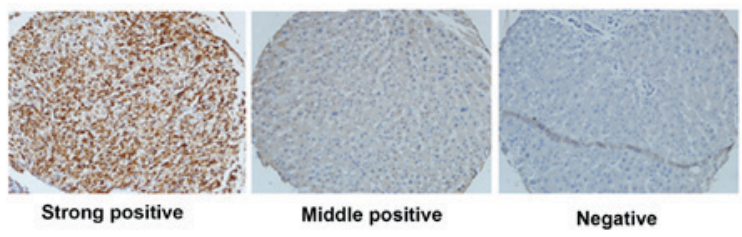

Figure 1. Expression level of coronin 3 in HCC clinical tissue samples. (A) Total RNAs from 20 primary tumor tissues and corresponding adjacent non-tumor tissues were extracted, and the mRNA expression level of coronin 3 was analyzed using reverse transcription-quantitative polymerase reaction. (B) Immunohistochemical staining of coronin 3 in 98 pairs of primary $\mathrm{HCC}$ tissues and their corresponding adjacent non-tumor tissues. HCC, hepatocellular carcinoma.

on ice for $5 \mathrm{~min}$. Cells were centrifuged at at $16,000 \mathrm{x} \mathrm{g}$ at $4^{\circ} \mathrm{C}$ for $15 \mathrm{~min}$, and the supernatant was transferred into a new tube. Afterwards, $100 \mu 150 \%$ resin slurry (contained in the Active Rac1 Pull-Down and Detection kit) was added to the spin cup and then centrifuged at 6,000 x g for $30 \mathrm{sec}$ and washed once with $400 \mu \mathrm{l}$ lysis/binding/wash buffer; subsequently, $20 \mu \mathrm{g}$ GST-human Pak1-PBD (contained in the Active Rac1 Pull-Down and Detection kit) was added to the spin cup containing the resin. A total of $700 \mu \mathrm{l}$ cell lysate (containing at list $500 \mu \mathrm{g}$ total proteins) was immediately transferred into the spin cup, and the sample was vortexed and incubated at $4^{\circ} \mathrm{C}$ for $1 \mathrm{~h}$ with gentle rocking. The sample was centrifuged at $6,000 \mathrm{x}$ g for $30 \mathrm{sec}$ and washed with $400 \mu 1$ lysis/binding/wash buffer three times. Finally, $50 \mu 1$ of $2 \mathrm{X}$ reducing buffer (125 mM Tris- $\mathrm{HCl}$ at $\mathrm{pH} 6.8,2 \%$ glycerol, 4\% SDS (w/v) and $0.05 \%$ bromophenol blue) was added to the resin sample and incubated at room temperature for $2 \mathrm{~min}$, then centrifuged at $6,000 \mathrm{x} \mathrm{g}$ for $2 \mathrm{~min}$. The eluted samples were heated for $5 \mathrm{~min}$ at $100^{\circ} \mathrm{C}$ and the samples were detected by western blotting using 12\% SDS-PAGE gels and an anti-Racl antibody (contained in the Active Rac1 Pull-Down and Detection kit).

Statistical analysis. All data are presented as the mean \pm standard deviation. Student's t-test was used for data analysis with using SPSS version 15 software (SPSS, Inc., Chicago, IL, USA). $\mathrm{P}<0.05$ was considered to indicate a statistically significant difference.

\section{Results}

Coronin 3 is overexpressed in HCC tumor tissues. To analyze the expression levels of coronin 3 in clinical tissue samples, qPCR and immunohistochemical staining assays were performed. The expression levels of coronin 3 in primary HCC tissues and their corresponding adjacent non-tumorous tissues were analyzed

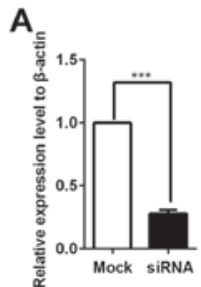

B

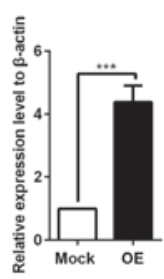

C
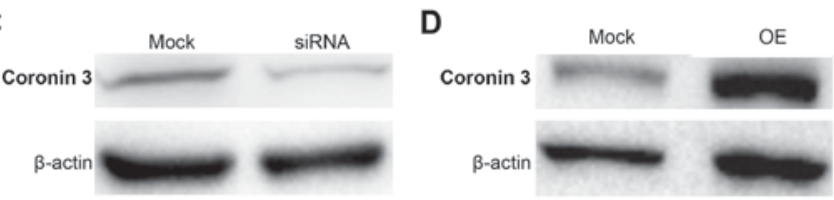

Figure 2. Coronin 3 is stably overexpressed and knocked down in HepG2 cells. Total RNAs were extracted and reverse transcribed into cDNA, then reverse transcription-quantitative polymerase chain reaction was applied to verify the (A) knockdown and (B) overexpression of coronin 3 at the mRNA level; each assay was repeated 3 times. Representative western blot images of coronin 3 protein expression levels following (C) knockdown and (D) overexpression. Data are presented as the mean \pm standard deviation. ${ }^{* * *} \mathrm{P}<0.001$. Mock, control; siRNA, coronin 3 small interfering RNA; OE, coronin 3 overexpression.

from 20 patients. As presented in Fig. 1A, the mRNA expression levels of coronin 3 were significantly increased in HCC tumor tissues compared with adjacent non-tumorous tissues. Furthermore, 98 paraffin embedded samples were immunohistochemically stained using a coronin 3 antibody; the results revealed that coronin 3 had significant stronger staining in $\mathrm{HCC}$ tumorous tissues, with a strong positive staining rate of $84.69 \%$, compared with a strong positive staining rate of $62.22 \%$ in adjacent non-tumorous tissues (Fig. 1B).

Coronin 3-regulated proteins are enriched in metabolism, and cellular and physiological processes. To further analyze the proteins that could be regulated by coronin 3 , coronin 3 was stably knocked down and overexpressed in HepG 2 cells. The overexpression or knockdown results were confirmed by RT-qPCR (Fig. 2A and B) and western blotting (Fig. 2C). These stable cells were cultured in MEM medium supplemented with 10\% FBS in T75 flasks to $90 \%$ confluency and then harvested; afterwards, $500 \mathrm{ng}$ total proteins were digested into peptides by trypsin and then the peptides underwent mass spectrometry analysis.

Overall, 453 and 2834 significantly differentially expressed proteins were identified in cells which stably overexpress or knockdown coronin 3, respectively, compared with their corresponding mock cells. In those dysregulated proteins, 249 proteins had a reversed tendency in coronin 3 overexpressed and knockdown cells [the protein was up-regulated (or down-regulated) when coronin 3 was overexpressed, but down-regulated (or up-regulated) when coronin 3 was knocked down, and vice versa]. These 249 proteins were defined as coronin 3-regulated proteins. Using these 249 proteins, Gene Ontology (GO) analysis was performed. As presented in Table III, 14.69, 13.55 and $7.21 \%$ proteins were enriched in cellular processes, physiological processes and metabolism, respectively. Pathway analysis demonstrated that these proteins were involved into 94 different signaling pathways, including cell cycle, insulin signaling, Wnt signaling 
and jak-stat signaling pathways. Some of these 249 proteins were also involved in human disease processes such as glioma [calcium/calmodulin-dependent protein kinase type II subunit delta), RAC-alpha serine/threonine-protein kinase (AKT1), G/S-specific cyclin-D1 (CCND1) and cyclin-dependent kinase 4 CDK4], chronic myeloid leukemia (AKT1, CCND1, CDK4 and S-phase kinase-associated protein 2) and small cell lung cancer (AKT1, CCND1, CDK4 and signal transducer and activator of transcription $5 \mathrm{~B})$.

Coronin 3 inhibits glucose-6-phosphatase catalytic subunit 3 (G6PC3) expression in HepG2 cells. To verify the mass spectrometry results, 4 upregulated [human epithelial cell adhesion molecule (hepCAM), zinc binding alcohol dehydrogenase domain containing 2 (ZADH2), mitochondrial calcium uptake 1 (MICU1) and squamous cell carcinoma-related oncogene (DCUN1D1)] and 1 downregulated (G6PC3) proteins were selected out of these 249 proteins to perform qPCR verification (primers were listed in Table II), as they have been reported to serve important roles in tumorigenesis, growth and metastasis of cancer (15-19), and had a marked fold change in the MS analysis. Among these 5 selected proteins, only G6PC3 demonstrated alterations in mRNA expression levels when coronin 3 expression was dysregulated in the verification experiments. As presented in Fig. 3, knockdown of coronin 3 promoted the expression of the G6PC3 (Fig. 3A), whereas overexpression of coronin 3 inhibited the expression of the G6PC3 (Fig. 3B). However, the other selected targets (hepCAM, ZADH2, MICU and DCUN1D1) demonstrated no significant differences in mRNA expression levels when coronin 3 was dysregulated, which may be due to the limitation of the MS technique itself (the repeatability of MS technique is always
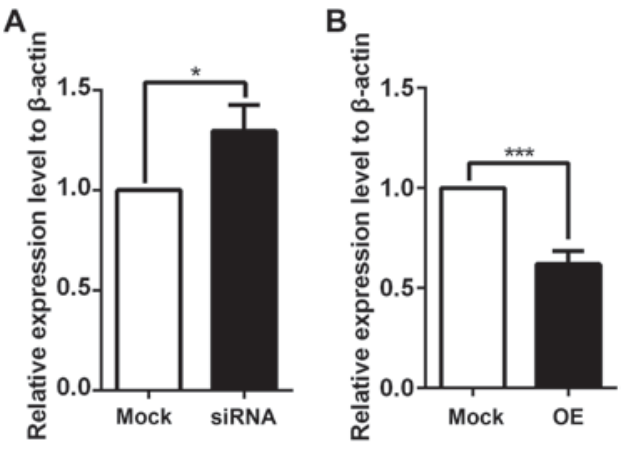

Figure 3. Expression of G6PC3 mRNA expression levels were analyzed by reverse transcription-quantitative polymerase chain reaction to verify the mass spectrometry results. mRNA expression levels of G6PC3 in (A) coronin 3 silenced and (B) overexpressing cells. Data are presented as the mean \pm standard deviation. ${ }^{*} \mathrm{P}<0.05,{ }^{* * *} \mathrm{P}<0.001$. Mock, control; siRNA: coronin 3 small interfering RNA, OE, coronin 3 overexpression. G6PC3, glucose-6-phosphatase catalytic subunit 3 .

low, and requires other techniques to confirm its results), or due to the expression change of selected targets at the protein level, rather than the mRNA level. Therefore, G6PC3 may be a downstream target of coronin 3 .

Using these 249 dysregulated proteins, Ingenuity Pathway Analysis (IPA) (https://www.qiagenbioinformatics.com/ products/ingenuity-pathway-analysis/) was performed. The results demonstrated that G6PC3 is a downstream target of inhibitors of differentiation 2 (ID2) protein, which is downstream of the Ras and TGF- $\beta$ signaling pathways, and ID2 expression is negatively associated with G6PC3 expression (Fig. 4). Additionally, G6PC3 was inhibited when ID2 was

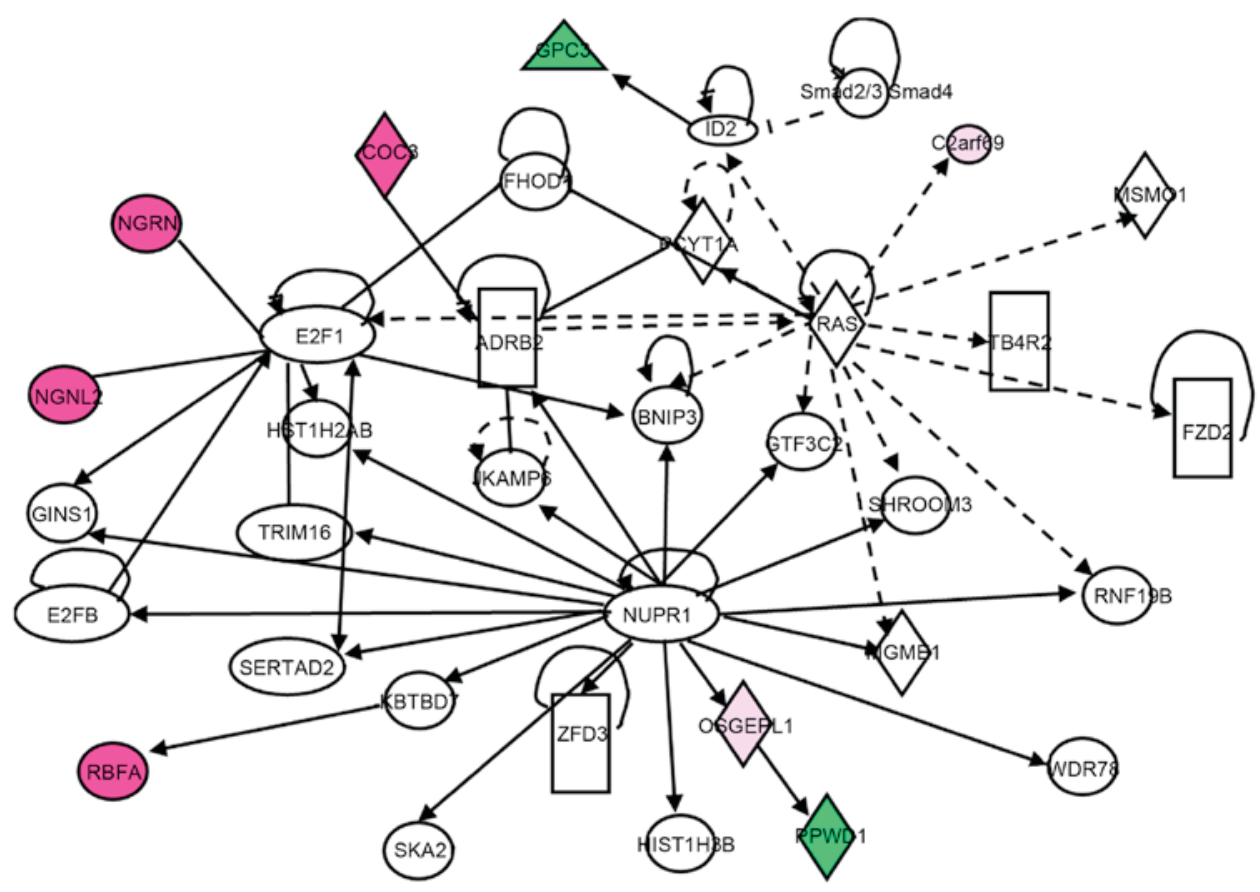

Figure 4. IPA of coronin 3-regulated proteins. A list of 249 coronin 3 regulated proteins, identified by mass spectrometry analysis, was uploaded into Ingenuity Pathway Analysis software for analysis. The green color indicates downregulation, and the red color indicates upregulation; the darker the color indicates high absolute Z-scores. Pointed arrowheads with straight lines indicate that the downstream node is expected to be activated if the upstream node is activated, while arrowheads with dotted lines indicate that the downstream node is expected to be inhibited if the upstream node is activated. IPA, Ingenuity Pathway Analysis. 


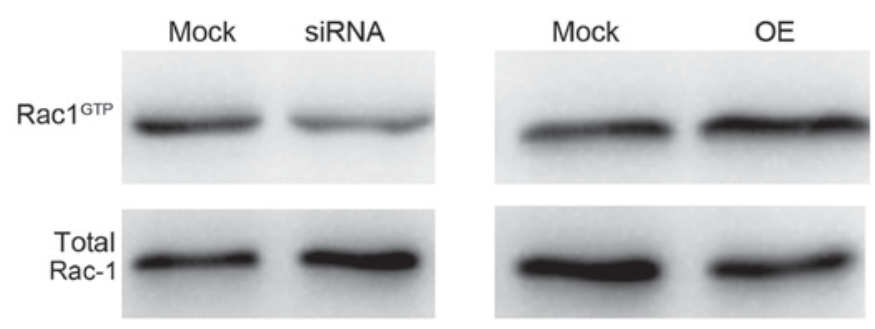

Figure 5. Rac-1 activity analysis in coronin 3 stably-overexpressing or knocked down cells. Equal amount of total cell lysates from control or stable cells were subjected to a GST-pull down assay using recombinant protein (GST)-PAK-CD. Afterwards, total Rac-1 and GTP-Rac-1 were analyzed by western blot analysis. Mock, control; siRNA, coronin 3 small interfering RNA; OE, coronin 3 overexpression; GST, glutathione S-transferase; Rac-1, Ras-related $\mathrm{C} 3$ botulinum toxin substrate 1 precursor.

activated (Fig. 4). It has been reported that Rac-1 is involved in both the Ras $(20,21)$ and TGF- $\beta(22,23)$ signaling pathways, and knockdown of coronin 3 could disrupt Rac-1 activity in HCC (10). Therefore, Rac-1 activity was further assessed using the above constructed stable cells. As presented in Fig. 5, Rac-1 activity was decreased when coronin 3 was downregulated, whereas was increased when coronin 3 was upregulated. These results indicated that coronin 3 may be involved in the TGF- $\beta$ and Ras signaling pathway via Rac-1.

\section{Discussion}

Coronin 3 (also known as coronin 1C) is the most widely expressed coronin protein in mammals $(3,24)$ and is a type I coronin protein which is part of a conserved family of WD-repeat-containing, actin-binding proteins. The coronin protein family comprise of seven members (coronin 1-6) (25). Coronins serve various roles in cell chemotaxis, cytokinesis, phagocytosis, locomotion and migration (24). Coronin 3 interacts with Arp2/3 and negatively regulates actin polymerization (5); in addition, it negatively regulates cell motility through regulation of cell-matrix adhesion via focal adhesion kinase (6). The present study confirmed that the expression level of coronin 3 was significantly increased in primary HCC tumor samples. This was consistent with early work that the upregulated expression of coronin 3 was strongly associated with tumor spontaneous pulmonary metastasis in a nude mice model of HCC $(10,11)$.

Recently, it has been reported that, besides HCC, coronin 3 is also involved in the process of human diffuse gliomas, gastric cancer and lung cancer. However, the biochemical mechanism of coronin 3 activity remains largely unknown, and the relevant downstream factors necessary for this activity require identification. The present study constructed cells stably over- expressing or knockdown of coronin 3. To uncover the proteins that may be regulated by coronin 3, label-free MS analysis was performed using whole cell lysates; 249 proteins were preliminarily identified to be regulated by coronin 3 indirectly or directly. These dysregulated proteins were enriched in cellular, physiological and metabolism processes, and were involved in 94 different signaling pathways according to KEGG. Previously, a list of 967 genes were identified as being downregulated in coronin 3-silenced lung cancer cells compared with the control by genome-wide gene expression analysis; and a total of 29 pathways were identified as being regulated by coronin 3 according to a KEGG pathway (8). In gastric cancer, the expression levels of 84 metastasis-associated genes were investigated in coronin 3 silenced cells, and 9 of these 84 genes were downregulated, while only 2 genes were upregulated; furthermore, the regulation of matrix metalloproteinase-9 (MMP-9) and cathepsin K by coronin 3 was further confirmed by qPCR in the MKN-45 and MKN-28-NM cell lines (9). However, MMP-9 and cathepsin $\mathrm{K}$ are not discovered in our current list, which might due to the differences of cell lines and cancer models.

Cancer cells utilize a variety of metabolic reprogramming strategies such as the Warburg Effect to survive in the presence of hypoxia and overgrowth $(26,27)$. Nevertheless, no matter how much of the metabolic program alteration, glucose is always the essential substrate for metabolic reactions. G6PC is one of the key enzyme that regulates glucose homeostasis and glycogenolysis. It has been reported that G6PC may be used as a specific enzyme marker for tumors of liver and kidney origin (28). In ovarian cancer, G6PC serves dual roles both in glucose metabolism and cell cycle control; knockdown of G6PC in ovarian cancer cells decreases cell proliferation, viability, invasiveness and anchorage-independent cell growth (29). In glioblastoma, G6PC is a key enzyme that has pro-malignant functions (30). In human primary HCC, qPCR analysis demonstrated that is G6PC significantly reduced compared with matching healthy liver tissues (19). G6PC3 is the third catalysis subunit of the G6PC. The present study demonstrated that coronin 3 could negatively regulate the expression of the G6PC3 in HepG2 cells, as assessed by mass spectrometry; and further analysis by IPA revealed that G6PC3 is negatively regulated by ID2, located downstream of the Ras and TGF- $\beta$ signaling pathways. It has been reported that IL-6/Stat3 signaling activated by microRNA-23a could directly target G6PC (19); and Rac-1, a Rho family small GTPase involved in many cell activities including cell cytoskeletal reorganization, cell growth, cell migration and invasion (31), could bind to and regulate Stat3 $(32,33)$. Recently, it has been reported that coronin 3 is closely associated with Rac-1 in HCC. In the present study, although the overexpression or knockdown of coronin 3 did not alter the protein expression levels of Rac-1, coronin 3 overexpression could significantly enhance Rac-1 activation by triggering the interaction between GTP and Rac-1. Therefore, coronin 3 may regulate G6PC3 expression through activating the Rac-1, then activated Rac1 may bind to and regulate Stat3, and thus inhibit the expression of G6PC3.

In conclusion, the present study demonstrated that Rac-1 is a key member of the TGF- $\beta$ and Ras signaling pathway, and coronin 3 may interact with these two signaling pathways by enhancing the activation of Rac- 1 . However, the detailed mechanisms require further elucidation. These results implicate coronin 3 as a potential therapeutic target for HCC.

\section{Acknowledgements}

The present study was supported by the National Natural Science Foundation of China (grant no. 31201008), the Educational and Research Project of Fujian Educational Department (grant no. JB13425), the Scientific Foundation of Fujian Province (grant no. 2015D001), the Scientific Foundation 
of Fuzhou Health Department (grant no. 2013-S-wq18), the Mengchao Hepatobiliary Hospital of Fujian Medical University (grant no. QDZJ-2014-004), the Science and Technology Bureau of Fuzhou City (grant no. 2014-S-139-1), the Fujian Provincial Health and Family Planning Commission (grant no. 2014-2-41) and the Special Research Development Fund of indirectly affiliated hospital of Fujian Medical University (grant no. FZS13004Y).

\section{References}

1. Iizaka M, Han HJ, Akashi H, Furukawa Y, Nakajima Y, Sugano S Ogawa $\mathrm{M}$ and Nakamura Y: Isolation and chromosomal assignment of a novel human gene, $\mathrm{CORO} 1 \mathrm{C}$, homologous to coronin-like actin-binding proteins. Cytogenet Cell Genet 88: 221-224, 2000.

2. McArdle B and Hofmann A: Coronin structure and implications. Subcell Biochem 48: 56-71, 2008.

3. Wick M, Bürger C, Brüsselbach S, Lucibello FC and Müller R: Identification of serum-inducible genes: Different patterns of gene regulation during $\mathrm{G} 0->\mathrm{S}$ and $\mathrm{G} 1->\mathrm{S}$ progression. J Cell Sci 107: 227-239, 1994.

4. Chang HY, Sneddon JB, Alizadeh AA, Sood R, West RB, Montgomery K, Chi JT, van de Rijn M, Botstein D and Brown PO: Gene expression signature of fibroblast serum response predicts human cancer progression: Similarities between tumors and wounds. PLoS Biol 2: E7, 2004.

5. Carlier MF and Pantaloni D: Control of actin assembly dynamics in cell motility. J Biol Chem 282: 23005-23009, 2007.

6. Samarin SN, Koch S, Ivanov AI, Parkos CA and Nusrat A: Coronin 1C negatively regulates cell-matrix adhesion and motility of intestinal epithelial cells. Biochem Biophys Res Commun 391: 394-400, 2010.

7. Thal D, Xavier CP, Rosentreter A, Linder S, Friedrichs B, Waha A, Pietsch T, Stumpf M, Noegel A and Clemen C: Expression of coronin-3 (coronin-1C) in diffuse gliomas is related to malignancy. J Pathol 214: 415-424, 2008.

8. Mataki H, Enokida H, Chiyomaru T, Mizuno K, Matsushita R, Goto Y, Nishikawa R, Higashimoto I, Samukawa T, Nakagawa M, et al: Downregulation of the microRNA-1/133a cluster enhances cancer cell migration and invasion in lung-squamous cell carcinoma via regulation of Coronin1C. J Hum Genet 60: 53-61, 2015.

9. Ren G, Tian Q, An Y, Feng B, Lu Y, Liang J, Li K, Shang Y, Nie Y, Wang X and Fan D: Coronin 3 promotes gastric cancer metastasis via the up-regulation of MMP-9 and cathepsin K. Mol Cancer 11: 67, 2012

10. Wang ZG, Jia MK, Cao H, Bian P and Fang XD: Knockdown of Coronin-1C disrupts Rac1 activation and impairs tumorigenic potential in hepatocellular carcinoma cells. Oncol Rep 29: 1066-1072, 2013.

11. Wu L, Peng CW, Hou JX, Zhang YH, Chen C, Chen LD and $\mathrm{Li}$ Y: Coronin-1C is a novel biomarker for hepatocellular carcinoma invasive progression identified by proteomics analysis and clinical validation. J Exp Clin Cancer Res 29: 17, 2010.

12. Tilley FC, Williamson RC, Race PR, Rendall TC and Bass MD: Integration of the Rac1- and actin-binding properties of Coronin-1C. Small GTPases 6: 36-42, 2015.

13. Livak KJ and Schmittgen TD: Analysis of relative gene expression data using real-time quantitative PCR and the 2(-Delta Delta C(T)) Method. Methods 25: 403-408, 2001

14. Gilar M, Olivova P, Daly AE and Gebler JC: Two-dimensional separation of peptides using RP-RP-HPLC system with different $\mathrm{pH}$ in first and second separation dimensions. J Sep Sci 28: 1694-1703, 2005.

15. Guan DX, Shi J,Zhang Y,Zhao JS, Long LY, Chen TW, Zhang EB, Feng YY, Bao WD, Deng YZ, et al: Sorafenib enriches epithelial cell adhesion molecule-positive tumor initiating cells and exacerbates a subtype of hepatocellular carcinoma through TSC2-AKT cascade. Hepatology 62: 1791-1803, 2015.
16. Auld DS and Bergman T: Medium- and short-chain dehydrogenase/reductase gene and protein families: The role of zinc for alcohol dehydrogenase structure and function. Cell Mol Life Sci 65: 3961-3970, 2008

17. Wang W, Xie Q, Zhou X, Yao J, Zhu X, Huang P, Zhang L, Wei J, Xie H, Zhou L and Zheng S: Mitofusin-2 triggers mitochondria $\mathrm{Ca} 2+$ influx from the endoplasmic reticulum to induce apoptosis in hepatocellular carcinoma cells. Cancer Lett 358: 47-58, 2015.

18. Fu W, Sun J, Huang G, Liu JC, Kaufman A, Ryan RJ, Ramanathan SY, Venkatesh T and Singh B: Squamous cell carcinoma-related oncogene (SCCRO) family members regulate cell growth and proliferation through their cooperative and antagonistic effects on cullin neddylation. J Biol Chem 291: 6200-6217, 2016.

19. Wang B, Hsu SH, Frankel W, Ghoshal K and Jacob ST: Stat3-mediated activation of microRNA-23a suppresses gluconeogenesis in hepatocellular carcinoma by down-regulating glucose-6-phosphatase and peroxisome proliferator-activated receptor gamma, coactivator 1 alpha. Hepatology 56: 186-197, 2012.

20. Zhou C, Licciulli S, Avila JL, Cho M, Troutman S, Jiang P, Kossenkov AV, Showe LC, Liu Q, Vachani A, et al: The Rac1 splice form Raclb promotes K-ras-induced lung tumorigenesis. Oncogene 32: 903-909, 2013.

21. Wu CY, Carpenter ES, Takeuchi KK, Halbrook CJ, Peverley LV, Bien H, Hall JC, DelGiorno KE, Pal D, Song Y, et al: PI3K Regulation of RAC1 Is required for KRAS-induced pancreatic tumorigenesis in mice. Gastroenterology 147: 1405-1416.e7, 2014.

22. Yamamoto N, Otsuka T, Kondo A, Matsushima-Nishiwaki R, Kuroyanagi G, Kozawa $\mathrm{O}$ and Tokuda $\mathrm{H}$ : Rac limits TGF- $\beta$-induced VEGF synthesis in osteoblasts. Mol Cell Endocrinol 405: 35-41, 2015.

23. Yu JR, Tai Y, Jin Y, Hammell MC, Wilkinson JE, Roe JS, Vakoc CR and Van Aelst L: TGF- $\beta /$ Smad signaling through DOCK4 facilitates lung adenocarcinoma metastasis. Genes Dev 29: 250-261, 2015.

24. Rybakin V and Clemen CS: Coronin proteins as multifunctional regulators of the cytoskeleton and membrane trafficking. Bioessays 27: 625-632, 2005.

25. Uetrecht AC and Bear JE: Coronins: The return of the crown. Trends Cell Biol 16: 421-426, 2006.

26. Lee AS: Glucose-regulated proteins in cancer: Molecular mechanisms and therapeutic potential. Cancer 14: 263-276, 2014.

27. Li B, Qiu B, Lee DS, Walton ZE, Ochocki JD, Mathew LK, Mancuso A, Gade TP, Keith B, Nissim I and Simonn MC: Fructose-1,6-bisphosphatase opposes renal carcinoma progression. Nature 513: 251-255, 2014.

28. Michals K, Pringle K, Pang EJ and Matalon R: Glucose-6-phosphatase as a marker for tumors of liver and kidney origin. Biochem Med 30: 127-130, 1983.

29. Guo T, Chen T, Gu C, Li B and Xu C: Genetic and molecular analyses reveal G6PC as a key element connecting glucose metabolism and cell cycle control in ovarian cancer. Tumour Biol 36: 7649-7658, 2015

30. Abbadi S, Rodarte JJ, Abutaleb A, Lavell E, Smith CL, Ruff W, Schiller J, Olivi A, Levchenko A, Guerrero-Cazares $\mathrm{H}$ and Quinones-Hinojosa A: Glucose-6-phosphatase is a key metabolic regulator of glioblastoma invasion. Mol Cancer Res 12: 1547-1559, 2014.

31. Moissoglu K, Slepchenko BM, Meller N, Horwitz AF and Schwartz MA: In vivo dynamics of Rac-membrane interactions. Mol Biol Cell 17: 2770-2779, 2006.

32. Simon AR, Vikis HG, Stewart S, Fanburg BL, Cochran BH and Guan KL: Regulation of STAT3 by direct binding to the Rac1 GTPase. Science 290: 144-147, 2000.

33. Sawada N, Li Y and Liao JK: Novel aspects of the roles of Rac1 GTPase in the cardiovascular system. Curr Opin Pharmacol 10: 116-121, 2010. 